\title{
Clonidine induced endothelium-dependent tonic contraction in circular muscle of the rat hepatic portal vein
}

\author{
Keiichi SHIMAMURA ${ }^{1}$, Miyuki TOBA ${ }^{1}$, Shinichi KimurA ${ }^{1}$, \\ Atsuko OHASHI ${ }^{1}$ and Kenji KITAMURA ${ }^{2}$ \\ ${ }^{1}$ Department of Clinical Pharmacology, Faculty of Pharmaceutical Sciences, Health \\ Sciences University of Hokkaido, 1757 Kanazawa, Ishikari-Tobetsu, Hokkaido 061- \\ 0293, Japan \\ ${ }^{2}$ Department of Physiological Science and Molecular Biology, Fukuoka Dental College, \\ Tamura, Sawara-ku, Fukuoka 814-0193, Japan
}

Received April 24, 2006; Accepted May 22, 2006

\begin{abstract}
Clonidine, an $\alpha_{2}$-agonist, has been shown to be useful in the treatment of hepatic portal hypertension in cirrhosis. The mechanism has been attributed to a clonidineinduced decrease in sympathetic activity. While clonidine has been shown to stimulate the $\alpha_{2}$-adrenoceptors of blood vessels, there is limited knowledge of the effects of clonidine on the circular muscle of the hepatic portal vein which regulates its blood flow. To investigate clonidine-induced contraction of the circular muscle of the hepatic portal vein and to clarify the possible role of the endothelium in the contraction, we examined the effects of clonidine on the isometric contraction of endothelium-intact and -removed ring preparations of the rat hepatic portal vein. In endothelium-intact preparations, clonidine caused a concentration-dependent increase in the amplitude of contractions. Inhibition of NO synthesis with $N^{\omega}$-nitro-L-arginine (L-NNA) elevated the resting tone, and increased the amplitude of the clonidine-induced contractions. Inhibition of cyclooxygenase by diclofenac did not change the amplitude of the clonidine-induced contractions observed both in the presence and absence of L-NNA. Application of a single concentration of clonidine induced a clear increase in amplitude of both twitch and tonic contractions. Twitch and tonic contractions induced by clonidine were inhibited by yohimbine. When the endothelium was damaged by sodium deoxycholate, tonic contractions induced by clonidine were completely suppressed, whereas the increase in twitch contractions was not influenced by chemical damage of the endothelium. Neither SKF-96365, a nonselective cation channel blocker, nor superoxide dismutase, a free radical scavenger, in the presence of catalase, changed the tonic contraction induced by clonidine. These results indicate that stimulation of $\alpha_{2}$-adrenoceptors enhanced twitch contractions and induced tonic contractions in the circular muscle of the rat hepatic portal vein, especially in the absence of NO. The latter, but not the former, occurs through an endothelium-dependent pathway.
\end{abstract}

Key words: clonidine, portal vein, tonic contraction, endothelium 


\section{Introduction}

In cirrhosis, treatment of hepatic portal hypertension is important to prevent varix formation and bleeding in the systemic circulation (Fleig, 1988). It has been reported that sympathetic nervous activity is increased in cirrhosis (Henriksen et al., 1984). In in vivo studies, clonidine prevented hepatic portal hypertension in hepatic portal vein-stenosed and cirrhotic rats (Roulot et al., 1989; Lin et al., 1991) and decreased hepatic wedge pressure in cirrhotic patients (Willett et al., 1986; Moreau et al., 1987). As these effects were associated with a decrease in the plasma noradrenaline concentration without a decrease in the hepatic blood flow, it was considered that clonidine decreased the postsinusoidal hepatic vascular outflow resistance (Willet et al., 1986; Esler et al., 1992) via a decrease in the sympathetic nerve efferent activity (Yomaida et al., 1979).

In in vitro experiments, clonidine has also been shown to contract longitudinal preparations of the canine hepatic portal vein (Furuta, 1988) while clonidine did not contract helical strips of the canine hepatic portal vein (Shoji et al., 1983). This would indicate that there are differences between the drug responses of the circular and longitudinal smooth muscle layers. Indeed, the relaxation responses to $\beta_{2}$-agonists were more sensitive in the circular smooth muscle layer than in the longitudinal smooth muscle layer of the rat hepatic portal vein (Rydningen et al., 1987). In the rat hepatic portal vein, contractions induced by various neurotransmitters were less sensitive in the circular smooth muscle layer when compared with the longitudinal smooth muscle layer (Mathison, 1983).

As a decrease in diameter induced prehepatic portal hypertension in the hepatic portal vein, (Szatmari et al., 2002), it is important to know the responses of the circular muscle to clonidine for an understanding of the actions of this drug in cirrhosis. However, there is little information available concerning the actions of clonidine on the circular smooth muscle layer of the hepatic portal vein.

The endothelial cell layer has been shown to regulate vascular contractility (Furchgott and Zawadski, 1981) and nitric oxide (NO), released from the endothelial cells by various agonists and conditions, plays a major role in the endothelium-dependent relaxation of vascular smooth muscle (Pearson and Vanhoutte, 1993). Clonidine is known to dilate various arteries and veins via both endothelium-dependent and -independent pathways (Angus et al., 1986; Thorin et al., 1998; Nishina et al., 1999; Lui et al., 2000; Fauaz et al., 2000). Figueroa et al. (2001) reported that endothelial $\alpha_{2 \mathrm{D}}$ subtype receptors were coupled to the NO synthetic pathway in the mesenteric artery of the rat. The presence of $\alpha_{2}$ receptors was also demonstrated on vascular smooth muscle cells (Lepretre et al., 1994; Macrez-Lepretre et al., 1995).

Histologically, the endothelium is located closer to the circular smooth muscle layer than the longitudinal smooth muscle layer, which would suggest that the smooth muscle cells of the circular layer may be more responsive to endothelial regulation in the rat hepatic portal vein than those of the longitudinal smooth muscle layer. Thus, to clarify the actions of clonidine on the rat portal vein, we performed experiments using ring preparations of the rat hepatic portal vein which were either endothelium-intact or denuded. 


\section{Materials and Methods}

Male Wistar rats weighing 200-300 g were anesthetized with $\mathrm{CO}_{2}$ and treated in accordance with "the Guiding principles for the care and use of laboratory animals", as approved by the Japanese Pharmacological Society.

After sagittal laparotomy and thoracotomy, the inferior vena cava was cut and the animal exsanguinated. The surface of the abdominal organs was cooled with a $4^{\circ} \mathrm{C}$ modified Tyrode's solution to prevent blood coagulation in the hepatic portal vein. The portal vein was isolated in Tyrode's solution and ring preparations cut under a binocular microscope. To make endothelium-denuded preparations, sodium deoxycholic acid $(0.75 \%)$ was perfused through the lumen of the vein for $20 \mathrm{sec}$. The composition of the Tyrode's solution (in $\mathrm{mM}$ ) was as follows: $137 \mathrm{NaCl}, 5.4 \mathrm{KCl}, 2.0 \mathrm{CaCl}_{2}, 1.0 \mathrm{MgCl}_{2}, 0.4 \mathrm{NaH}_{2} \mathrm{PO}_{4}, 11.9 \mathrm{NaHCO}_{3}$ and 5.6 glucose (pH 7.3). High K (50 mM) solution was made by replacement of equimolar concentrations of $\mathrm{NaCl}$ with $\mathrm{KCl}$ and nominally Ca-free solution was made by omitting $\mathrm{CaCl}_{2}$. The ring preparations were mounted horizontally in an organ bath $\left(2.5 \mathrm{ml}\right.$ in volume) at $37^{\circ} \mathrm{C}$, and aerated with a mixture of $95 \% \mathrm{O}_{2}-5 \% \mathrm{CO}_{2}$. The force of isometric contractions was measured using a force-displacement transducer (U-gage 10G, Minebea, Karuizawa, Japan) equipped with a strain amplifier (AS2102, NEC, Tokyo, Japan) and recorded on a thermal-pen recorder (Linearcorder WR3310, Graphtec, Tokyo, Japan).

The amplitudes of the twitch contractions were measured from the basal tone level to the peak of the spontaneous twitch contractions. The amplitude of the tonic contractions were measured from the basal tone level between the twitch contractions obtained before the application of clonidine. Amplitudes of contractions were measured after the tonic contraction reached a stable level.

\section{Drugs}

Clonidine, diclofenac, superoxide dismutase (SOD), catalase, $N^{\omega}$-nitro-L-arginine (L-NNA), sodium nitroprusside (SNP) and sodium deoxycholate are purchased from Wako Pure Chemical (Osaka, Japan). Yohimbine, and 1-[ $\beta$ (3-[4-methoxyphenyl] propoxy)-4-methoxyphenethyl]-1Himidazole (SKF-96365) are from Sigma (St. Louis, MO, USA).

\section{Data analysis}

Results are expressed as the mean \pm S.E.M. with the number of animals in parenthesis. Statistical significance was assessed by means of the Mann-Whitney test using conventional statistic software (GraphPad Prism, San Diego, USA). $P<0.05$ was considered to be significant.

\section{Results}

\section{Effects of clonidine on endothelium-intact preparations}

Ring preparations of the rat hepatic portal vein (endothelium intact) exhibited spontaneous small twitch contractions with an amplitude of $13.4 \pm 4.8 \%(\mathrm{n}=24)$ of $50 \mathrm{mM}$ K-induced contracture, with a frequency of $5.6 \pm 0.6$ contractions per min $(n=18)$ (which may reflect the 
A
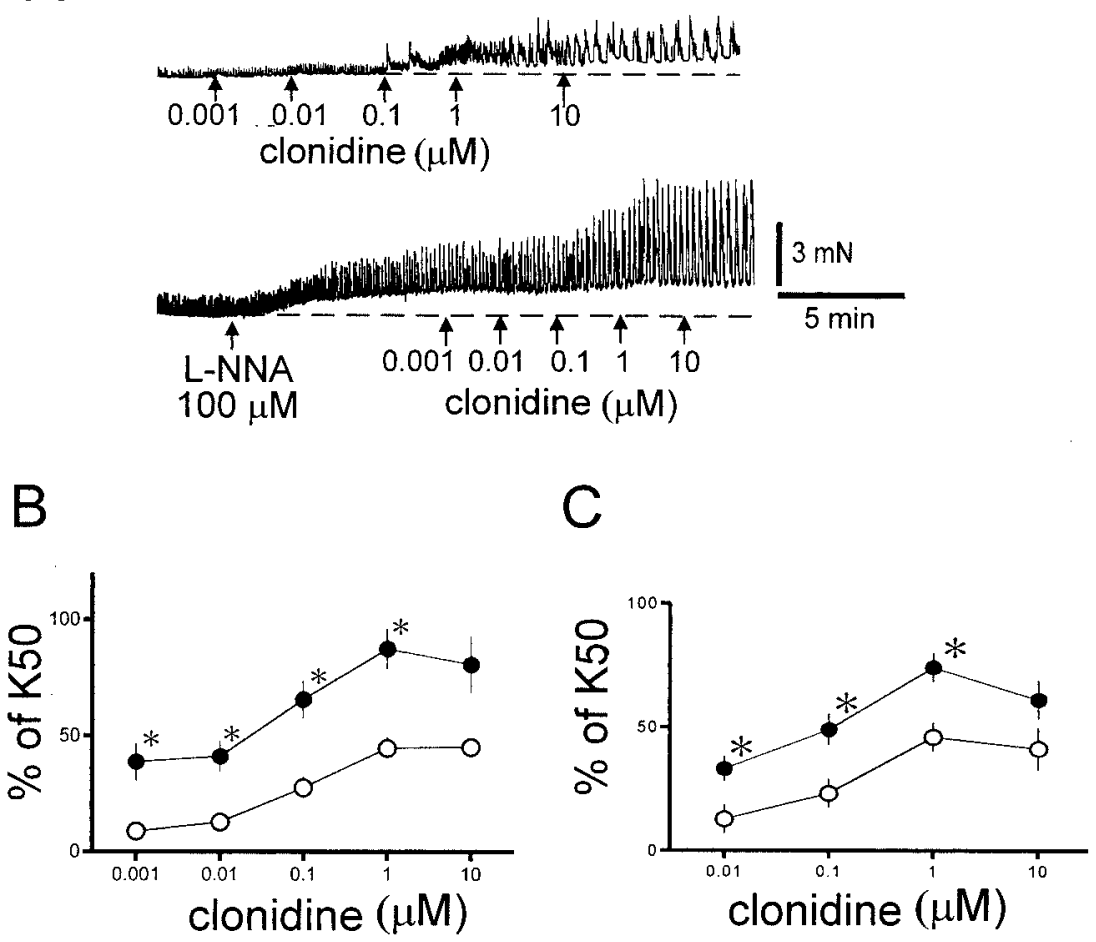

Fig. 1. Effects of clonidine on the contractions of endothelium-intact ring preparations of the rat hepatic portal vein in the absence and presence of $100 \mu \mathrm{M}$ L-NNA. A: Typical traces showing the clonidine induced augmentation of the contractions. Increasing concentrations of clonidine were applied cumulatively. Upper and lower traces were recoded in the absence and presence of L-NNA, respectively. Broken lines indicate tonic tension levels before application of clonidine (upper trace) and L-NNA (lower trace), respectively. B: Relationships between the amplitude of twitch contractions and the concentration of clonidine in the absence (open circle) and presence (filled circle) of $100 \mu \mathrm{M}$ L-NNA. The amplitudes of twitch contractions were measured from the broken line in A and expressed as a \% of the $50 \mathrm{nM} \mathrm{K}$ contracture. Number of observations for each data is $6-8$. Asterisks indicate a significant difference from the control $(P<0.05)$. C: Effects of clonidine on contractions of rat hepatic portal vein in endothelium-intact ring preparations in the presence of $10 \mu \mathrm{M}$ diclofenac, in both the absence and presence of $100 \mu \mathrm{M}$ L-NNA. All data were recorded in the presence of diclofenac, and increasing concentrations of clonidine were cumulatively applied to the tissue in the absence (open circle) and presence (filled circle) of $100 \mu \mathrm{M}$ L-NNA. The amplitudes of the twitch contractions were expressed as a \% of the $50 \mathrm{mM} \mathrm{K}$ contracture. Number of preparations for each point is 5-6. Asterisks indicate a significant difference from the control $(P<0.05)$.

activity of the longitudinal smooth muscle layer; Shimamura et al., 2003). Cumulative application of clonidine $(0.001$ to $10 \mu \mathrm{M})$ induced a concentration-dependent increase in the amplitudes of both the twitch and tonic contractions (Fig. 1A upper trace and 1B open circles).

Application of L-NNA $(100 \mu \mathrm{M})$ increased the amplitude of the twitch contractions and produced a tonic contraction $(19.8 \pm 4.8 \%, \mathrm{n}=24$, and $19.9 \pm 0.2 \%, \mathrm{n}=21$, of the amplitude of the 50 $\mathrm{mM}$ K-induced contracture, respectively). This indicates that nitric oxide is spontaneously 
A
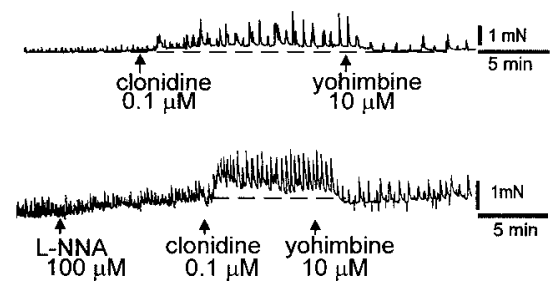

tonic

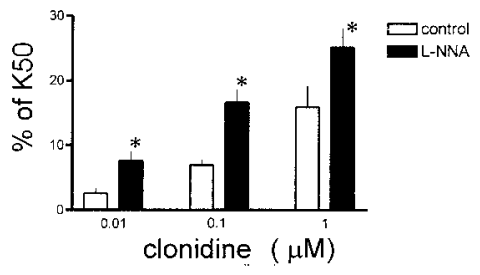

Fig. 2. Contractions induced by a single administration of clonidine and the effects of yohimbine and L-NNA in endothelium-intact preparations. A: Typical traces of clonidine $(0.1 \mu \mathrm{M})$-induced responses in the absence (upper trace) and presence (lower trace) of L-NNA. Broken lines indicates basal tone before application of clonidine. B: Relationships between the amplitude of the tonic contraction and the concentration of clonidine in the absence (open column) and presence (filled column) of $100 \mu \mathrm{M}$ L-NNA. The amplitudes of tonic contraction were measured from the broken line in A after the clonidine-induced contraction became stable, and expressed as a $\%$ of the $50 \mathrm{mM} \mathrm{K}$ contracture. Number of observations is $6-8$ in each data. Asterisks indicate a significant difference from the control $(P<0.05)$.

released in ring preparations of the rat hepatic portal vein. The L-NNA-induced contraction was inhibited by both sodium nitroprusside and nicardipine, a $\mathrm{Ca}$ antagonist.

To examine the contribution of nitric oxide to the clonidine-induced contraction, the amplitudes of twitch contractions induced by various concentrations of clonidine were compared with those recorded in the presence of L-NNA. As shown in Fig. 1B, when preparations were pretreated with L-NNA, clonidine still induced contractions.

Diclofenac, a cyclooxygenase inhibitor, did not alter the increase in the amplitude of the twitch contractions induced by clonidine both in the absence and presence of L-NNA (Fig. 1C). These results indicate that metabolites of cyclooxygenase did not participate on the clonidineinduced contraction.

To avoid any contribution of the time- and precondition-dependent influences on the clonidine-induced contraction, we applied clonidine in a single dose to preparations instead of as a cumulative application. As shown in Fig. 2, pretreatment with L-NNA significantly augumented the clonidine-induced tonic contractions at concentrations of $0.01,0.1$ and $1 \mu \mathrm{M}$. In nominally Ca-free medium, preparations did not exhibit spontaneous contractions, and neither L-NNA nor clonidine induced any contraction (data not shown). Application of nicardipine also inhibited the generation of spontaneous and clonidine-induced tonic contractions (data not shown).

Basal tension recorded in the presence of spontaneously released NO (basal NO), recorded before application of L-NNA, was restored by administration of SNP in the presence of L-NNA. To assess the possible contribution of NO in clonidine-induced contractions, we examined the effects of clonidine on the tonic contractions obtained in both the L-NNA-treated and untreated preparations in the presence of diclofenac. After an L-NNA-induced tonic contraction was achieved, the contraction was suppressed back to the basal tension level by application of SNP 

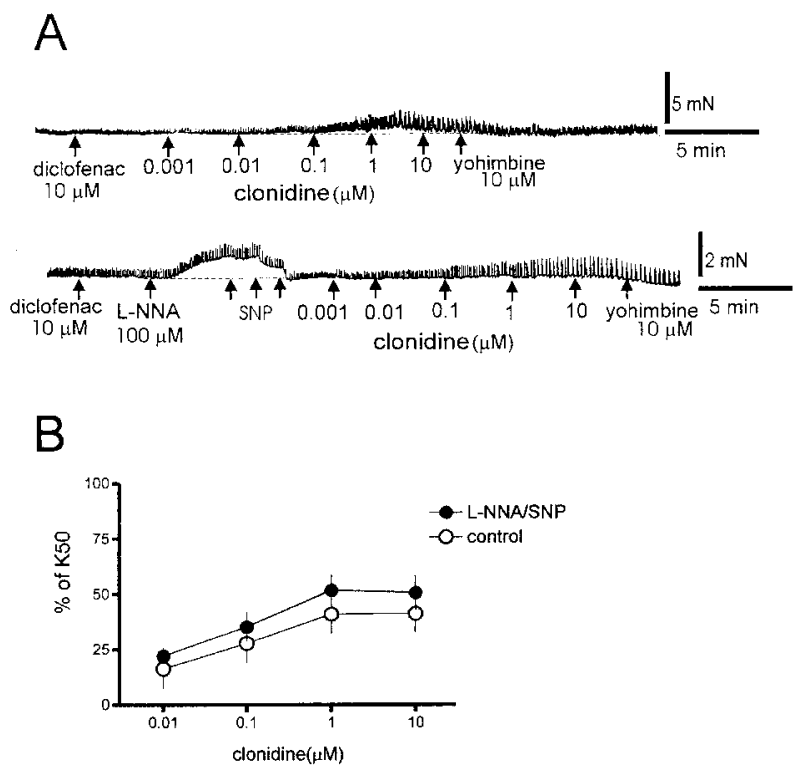

Fig. 3. Clonidine-induced contractions in endothelium-intact ring preparations in the presence of diclofenac, under both control and NO synthesis-inhibited conditions without change in basal tension. A: Clonidine-induced contractions without (upper trace) and with NO synthesis inhibition (L-NNA/SNP: bottom trace). In L-NNA/SNP, a minimal amount of SNP was applied cumulatively (10 to $300 \mathrm{nM}$ ) at arrows to inhibit L-NNA-induced tone. B: A summary graph showed clonidine-induced contractions were similar in control and L-NNA/SNP. Each point is the mean \pm S.E. 4-6 preparation.

and clonidine was then applied cumulatively. As shown in Fig.3B, the amplitude of the clonidine-induced contractions in both L-NNA-treated and untreated preparations did not differ, indicating that there was no involvement of NO in the clonidine-induced contraction.

Yohimbine, an $\alpha_{2}$ antagonist, inhibited the amplitude of the clonidine-induced twitch and tonic contractions to the control level both in the absence and presence of L-NNA (Figs. 2A and $3 \mathrm{~A})$. Thus, both the augmentation of twitch contractions and the generation of a tonic contraction by clonidine occur via $\alpha_{2}$-adrenoceptor stimulation.

\section{Clonidine-induced tonic contraction in endothelium-intact and-removed preparations}

To study the contribution of the endothelium, the effects of clonidine were compared in endothelium-intact and -removed preparations. In endothelium-intact preparations, $1 \mu \mathrm{M}$ clonidine produced tonic contractions with an amplitude of $17.3 \pm 2.7 \%(\mathrm{n}=11)$ of the $50 \mathrm{mM} \mathrm{K}$ induced contracture. On the other hand, in endothelium-removed preparations, the amplitudes of the tonic contractions induced by application of the same concentration of clonidine were reduced to $2.5 \pm 1.2 \%(\mathrm{n}=7)$ of the $50 \mathrm{mM} \mathrm{K}$-induced contracture (Fig. 4). In the presence of diclofenac, L-NNA and $1 \mu \mathrm{M}$ clonidine both produced marked tonic contractions in endotheliumintact preparations $(14.5 \pm 2.5 \%(\mathrm{n}=11)$ and $22.9 \pm 5.0 \%(\mathrm{n}=11)$ of the $50 \mathrm{mM}$ K-induced contractions, respectively), whereas neither L-NNA nor clonidine produced tonic contractions in 
A

$E(+)$

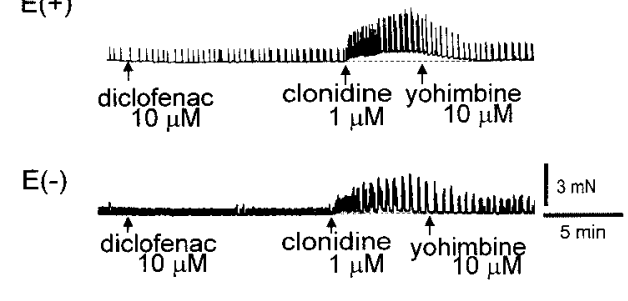

B

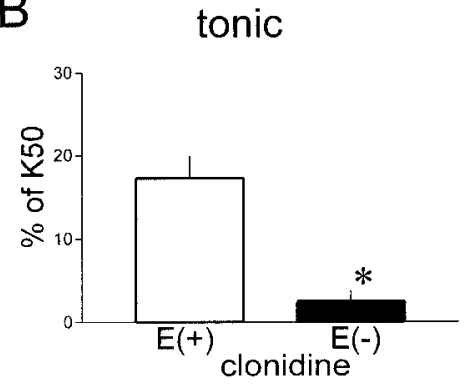

Fig.4. Roles of endothelium on the clonidine-induced contractions in the presence of $10 \mu \mathrm{M}$ diclofenac. A: Typical traces were shown with endothelium-intact $(\mathrm{E}(+)$; upper trace) and removed $(\mathrm{E}(-)$; lower trace) ring preparations. Diclofenac $(10 \mu \mathrm{M})$, clonidine $(1$ $\mu \mathrm{M})$ and yohimbine $(10 \mu \mathrm{M})$ were applied at arrows. Broken lines indicate basal tension level of contraction before application of clonidine. B: Mean amplitudes of the tonic contractions induced by $1 \mu \mathrm{M}$ clonidine in the endothelium-intact (open column) and -removed (filled column) hepatic portal vein. The amplitudes of tonic contraction were measured from the broken line in A after the clonidine-induced contractions became stable, and are expressed as a \% of the $50 \mathrm{mM} \mathrm{K}$ contracture. Number of observations is 6 for $\mathrm{E}(+)$, and 8 for $\mathrm{E}(-)$. Asterisks indicate a significant difference from $\mathrm{E}(+)(P<0.05)$.

endothelium-removed preparations (Fig. 5). Augmentation of the twitch contractions induced by clonidine was not suppressed by endothelium-removal, in the presence of diclofenac and LNNA. The amplitude of $1 \mu \mathrm{M}$ clonidine-induced twitch contractions in endothelium-intact and removed preparation was $80 \pm 15 \%(n=6)$ and $81 \pm 15 \%(n=6)$ of the $50 \mathrm{mM} \mathrm{K}$-induced contracture, respectively. Thus, augmentation of twitch contractions and induction of tonic contractions by clonidine occurred by way of different mechanisms; the former contractions are endothelium-independent while the latter are endothelium-dependent.

In the presence of L-NNA, SKF-96365 (a nonselective cation channel inhibitor) did not inhibit clonidine-induced tonic contractions (Fig. 6B). Pretreatment of the preparations with 150 $\mathrm{U} / \mathrm{ml} \mathrm{SOD}$ in the presence of $1200 \mathrm{U} / \mathrm{ml}$ catalase did not change the $1 \mu \mathrm{M}$ clonidine-induced tonic contractions (Fig. 6C).

\section{Discussion}

Since the first finding of endothelium-dependent relaxation, many agonists, including NO, have been shown to release endothelium-derived relaxing factor (EDRFs) which inhibits vascular smooth muscle contraction (Furchgott and Zawadski, 1981; Pearson and Vanhoutte, 1993). In both longitudinal and circular muscle preparations of the hepatic portal vein, NO was shown to inhibit contraction, suggesting that contractility of the hepatic portal vein was regulated by NO (Feletou et al., 1989; Shimamura et al., 2000). However, acetylcholine-induced EDRF released from either aorta or femoral artery failed to change the spontaneous contraction of the rat portal vein longitudinal muscle preparation (Vedernikov et al., 1987; Feletou et al., 1989). Thus, the possible contributions of both EDRF and other factors released from the endothelium on the smooth muscle of the hepatic portal vein were still obscure. 


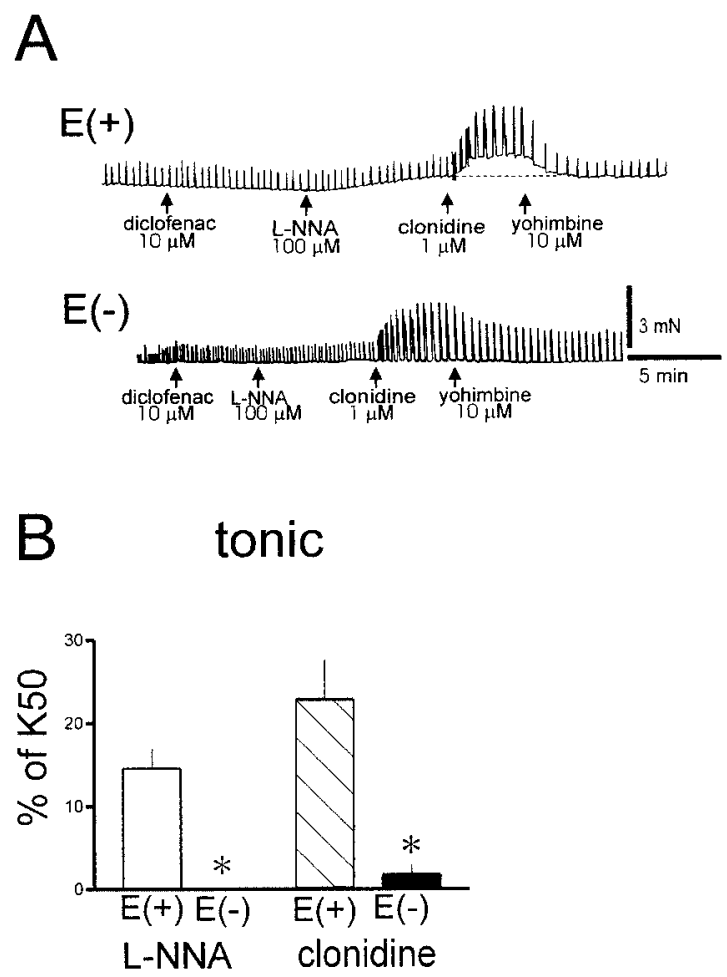

Fig. 5. Roles of endothelium on the L-NNA $(100 \mu \mathrm{M})$ and clonidine $(1 \mu \mathrm{M})$-induced contractions in the rat hepatic portal vein in the presence of diclofenac $(10 \mu \mathrm{M})$. A: Typical traces are shown with endothelium-intact $(\mathrm{E}(+)$; upper trace) and removed $(\mathrm{E}(-)$; lower trace) ring preparations. Diclofenac, L-NNA and clonidine were applied at arrows. Broken lines indicate basal tone of contraction induced by L-NNA. B: Mean amplitudes of the tonic contractions induced by $100 \mu \mathrm{M}$ L-NNA and $1 \mu \mathrm{M}$ clonidine in the endothelium-intact (open column for L-NNA; hatched column for clonidine) and endothelium-removed (filled column for L-NNA; filled hatched column for clonidine) preparations. The amplitudes of clonidine-induced tonic contractions were measured from the broken line after the clonidine-induced contractions became stable, and are expressed as a \% of the $50 \mathrm{mM} \mathrm{K}$ contracture. Number of observations is 6 for $\mathrm{E}(+)$, and 8 for $\mathrm{E}(-)$. Asterisks indicate a significant difference from $\mathrm{E}(+)$ $(P<0.05)$.

Basal release of NO has been demonstrated in both the rat aorta (Martin et al., 1986) and the rabbit saphenous vein (McGrath et al., 1990). In the present experiments, we observed that L-NNA elevated the basal tone of ring preparations of the rat hepatic portal vein (Figs. 1 and 2), and confirmed that NO was spontaneously released in these preparations (Shimamura $e t$ al., 2000).

The present study has shown that clonidine enhanced the amplitude of twitch contractions and generated tonic contractions in ring preparation of the rat hepatic portal vein. Although the twitch contractions induced by clonidine were augmented by L-NNA, removal of the endothelium did not suppress the augmentation (Figs. 4 and 5). As augmentation of the twitch contractions induced by clonidine was inhibited by yohimbine, the augmenting action of 


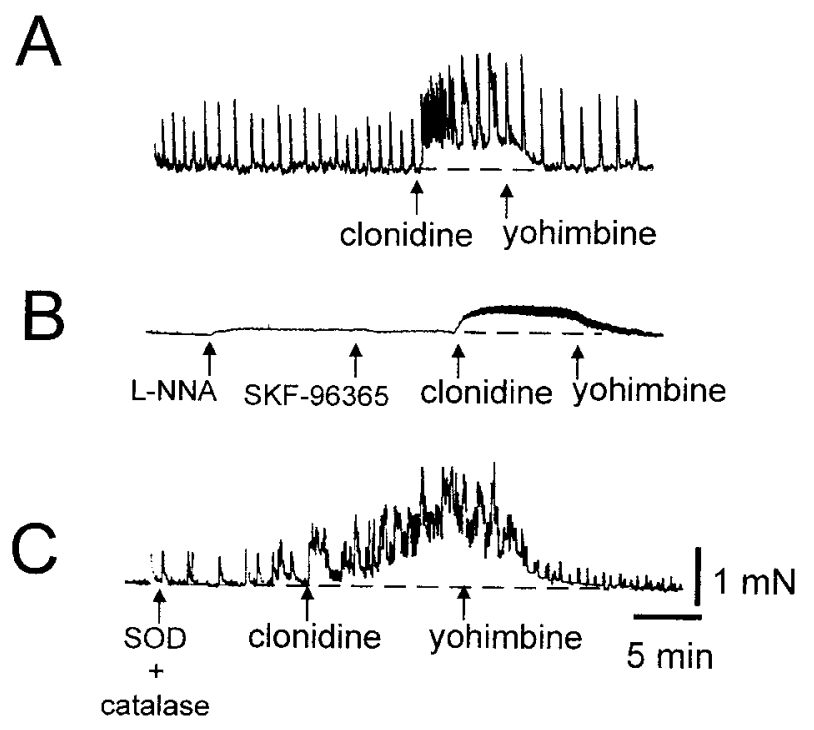

Fig. 6. Effects of SKF-96365 and superoxide dismutase (SOD; $150 \mathrm{U} / \mathrm{ml}$ ) in the presence of catalase $(1,200 \mathrm{U} / \mathrm{ml})$ on clonidine-induced contractions recorded in endotheliumintact rat hepatic portal vein ring preparations. A: control, B: SKF-96365, C: SOD with catalase. In all cases, clonidine $(1 \mu \mathrm{M})$ was applied at the arrows in the presence of LNNA. Note that both drugs did not inhibit clonidine-induced tonic contractions.

clonidine involves $\alpha_{2}$ receptor stimulation of vascular smooth muscle cells. The presence of $\alpha_{2}$ receptors on smooth muscle cells of vascular muscle has been reported (Fauaz et al., 2000). Augmentation of L-type Ca channel currents by clonidine was also reported in isolated smooth muscle cells of the rat hepatic portal vein (Lepretre et al., 1994; Macrez-Lepretre et al., 1995). In the present experiments, we did not examine the possible contribution of $\alpha_{2}$ receptors at prejunctional nerve terminals, however, it is unlikely that clonidine-induced augmentation of twitch contractions occurred via prejunctional $\alpha_{2}$ receptor stimulation, as prejunctional $\alpha_{2}$ receptors are involved with the autoinhibition of norepinephrine release (Bobalova and Mutafova-Yambolieva, 2001).

The involvement of $\alpha_{2}$ agonist-induced NO release in the contraction was not marked, as the spontaneously released NO could be restored by SNP (Fig. 3). Thus our observation may support previous studies (Feletou et al., 1989; Vedernikov et al., 1987) which showed negative evidence for acetylcholine-mediated EDRF in the rat portal vein. Tonic contractions induced by clonidine were endothelium-dependent (Fig. 4), and L-NNA enhanced the amplitude of these tonic contractions. Thus, clonidine stimulates the release of a contractile factor or inhibits the release of a relaxing factor from the endothelium of the rat hepatic portal vein. When NO synthesis was blocked by L-NNA, the tonic contractions induced by clonidine were markedly enhanced (Fig. 2). Therefore, inhibition of NO synthesis may not be involved in the clonidineinduced contractions, at least not in the presence of L-NNA.

Several possible candidates for the contractile factor involved in clonidine-induced tonic contractions were examined, such as superoxide, prostanoids and endothelin. Although 
superoxide has been shown to contribute to endothelium-dependent contraction (Katusic and Vanhoutte, 1989; Yang et al., 2002), the combination of SOD with catalase did not inhibit clonidine-induced tonic contractions. Such a combination of enzymes was reported to rapidly metabolize superoxide (Yang et al., 2003), and our results showed that the contribution of superoxide to the clonidine-induced tonic contractions may be negligible. Diclofenac, a cyclooxygenase inhibitor, failed to change the amplitude of the tonic contractions induced by clonidine in the presence and absence of L-NNA. As diclofenac did not produce any change on the contractility of the rat portal vein in the present experiments, cyclooxygenase metabolites did not contribute to the clonidine-induced responses in the rat hepatic portal vein. A possible contribution of nonselective cation channel activation via endothelial $\alpha_{2}$ receptor stimulation was also excluded, as SKF-96365, a nonselective cation channel inhibitor, did not suppress clonidineinduced tonic contractions. Thus, the detailed mechanism involved in the endotheliumdependent contraction caused by clonidine remains to be elucidated.

In conclusion, our results indicate that clonidine induces endothelium-dependent tonic contractions in rat hepatic portal vein ring preparations. In clinical use, the plasma concentration of clonidine is approximately $1 \mathrm{ng} / \mathrm{ml}$ in systemic veins (Wing et al., 1977). In the present study we used clonidine at a 100 times higher concentration, which may be achieved in hepatic portal venous plasma after oral administration. In the absence of NO, clonidine may induce prehepatic portal hypertension by a tonic contraction of the circular smooth muscle of the hepatic portal vein and this untoward effect needs to be considered in the treatment of portal hypertension by oral administration of clonidine.

\section{Acknowledgements}

This study was supported in part by the Academic Science Frontier Project of the Ministry of Education, Culture, Sports, Science and Technology, Japan.

\section{References}

Angus, J.A., Cocks, T.M. and Satoh, K. (1986). The $\alpha$-adrenoceptors on endothelial cells. Fed. Proc. 45: 2355-2359.

Bobalova, J. and Mutafova-Yambolieva, V.N. (2001). Presynaptic $\alpha_{2}$-adrenoceptor-mediated modulation of adenosine $5^{\prime}$ triphosphate and noradrenaline corelease: differences in canine mesenteric artery and vein. J. Auton. Pharmacol. 21: 47-55.

Esler, M., Dudley, F., Jennings, G., Debinski, H., Lambert, G., Jones, P., Crotty, B. Colman, J. and Willett, I. (1992). Increased sympathetic nervous activity and the effects of its inhibition with clonidine in alcoholic cirrhosis. Ann. Int. Med. 116: 446-455.

Fauaz, G., Feres, T., Borges, A.C. and Paiva, T.B. (2000). Alpha-2 adrenoceptors are present in rat aorta smooth muscle cells, and their action is mediated by ATP-sensitive $\mathrm{K}^{+}$channels. $B r . J$. Pharmacol. 131: 788-794.

Feletou, M., Hoeffner, U. and Vanhoutte, P.M. (1989). Endothelium-dependent relaxing factors do not affect the smooth muscle of portal-mesenteric vein. Blood Vessels 26: 21-32.

Figueroa, X.F., Poblete, M.I., Boric, M.P., Mendizábal, V.E., Adler-Graschinsky, E. and Huidobro-Toro, J.P. (2001). Clonidine-induced nitric oxide-dependent vasorelaxation mediated by endothelial 
$\alpha_{2}$-adrenoceptor activation. Br. J. Pharmacol. 134: 957-968.

Fleig, W.E. (1988). Pharmacological methods for the prevention of the first and recurrent bleeding from esophageal varices. Z. Gastroenterol. 26 (Suppl. 2): 40-48.

Furchgott, R.F. and Zawadski, J.V. (1981). The obligatory role of the endothelial cells in the relaxation of arterial smooth muscle cells by acetylcholine. Nature 288: 373-376.

Furuta, T. (1988). Precontraction-induced contractile response of isolated canine portal vein to alpha-2 adrenoceptor agonists. Naunyn-Schmiedeberg's Arch. Pharmacol. 337: 525-530.

Henriksen, J.H., Ring-Larsen, H., Kanstrup, I.L. and Christensen, N.J. (1984). Splanchnic and renal elimination and release of catecholamines in cirrhosis. Evidence of enhanced nervous activity in patients with decompensated cirrhosis. Gut 25: 1034-1043.

Katusic, Z.S. and Vanhoutte, P.M. (1989). Superoxide anion is an endothelium-derived contracting factor. Am. J. Physiol. 257: H33-H37.

Lepretre, N., Mironneau, J. and Morel, J.L. (1994). Both $\alpha_{1 A^{-}}$and $\alpha_{2 \mathrm{~A}}$-adrenoceptor subtypes stimulate voltage-operated L-type calcium channels in rat portal vein myocytes. Evidence for two distinct transduction pathways. J. Biol. Chem. 269: 29546-29552.

Lin, H.C., Soubrane, O. and Lebrec, D. (1991). Prevention of portal hypertension and postsystemic shunts by early chronic administration of clonidine in conscious portal vein-stenosed rats. Hepatol. 14: 325-330.

Lui, A.H., McManus, B.M. and Laher, I. (2000). Endothelial and myogenic regulation of coronary artery tone in the mouse. Eur. J. Pharmacol. 410: 25-31.

Macrez-Lepretre, N., Ibarrondo, J., Arnaudeau, S., Morel, J.L., Guillon, G. and Mironneau, J. (1995). A

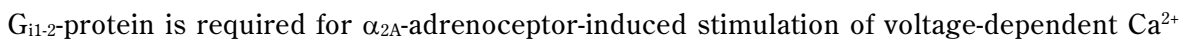
channels in rat portal vein myocytes. Pflügers Arch. 430: 590-592.

Martin, W., Furchgott, R.F., Villani, G.M. and Jothianandan, D. (1986). Depression of contractile responses in rat aorta by spontaneously released endothelium-derived relaxing factor. $J$. Pharmacol. Exp. Ther. 237: 529-538.

Mathison, R. (1983). Actions of neurotransmitters and peptides on longitudinal and circular muscle of the rat portal vein. J. Pharm. Pharmacol. 35: 34-37.

McGrath, J.C., Monaghan, S., Templeton, A.G.B. and Wilson, V.G. (1990). Effect of basal and acetylcholine-induced release of endothelium-derived relaxing factor on contraction to $\alpha$ adrenoceptor agonists in a rabbit artery and corresponding veins. Br. J. Pharmacol. 99: 77-86.

Moreau, R., Lee, S.S., Hadengue, A., Braillan, A. and Lebrec, D. (1987). Hemodynamic effects of a clonidine-induced decrease in sympathetic tone in patients with cirrhosis. Hepatol. 7: 149-154.

Nishina, H., Ozaki, T., Hanso, M.A. and Poston, L. (1999). Mechanisms of noradrenaline-induced vasorelaxation in isolated femoral arteries of the neonatal rat. Br. J. Pharmacol. 127: 809-812.

Pearson, P.J. and Vanhoutte, P.M. (1993). Vasodilator and vasoconstrictor substances produced by the endothelium. Rev. Physiol. Biochem. Pharmacol. 122: 1-67.

Roulot, D., Braillon, A., Gaudin, C., Ozier, Y., Girod, C. and Lebrec, D. (1989). Mechanisms of a clonidine-induced decrease in portal pressure in normal and cirrhotic conscious rats. Hepatol. 10: $477-481$.

Rydningen, H.T., Omland, T., Opstad, P.K. and Helle, K.B. (1987). Comparison of VIP and $\beta_{2^{-}}$ adrenoceptor-induced relaxations in the circular and longitudinal smooth muscle layers of the rat portal vein. Acta. Physiol. Scand. 130: 601-607.

Shimamura, K., Zou, L.-B., Matsuda, K., Sekiguchi, F., Yamamoto, K. and Sunano, S. (2000). Role of nitric oxide in the contraction of circular muscle in the rat portal vein. Pflügers Arch. 440: 435439 .

Shimamura, K., Zhou, M., Toba, M., Kimura, S., Higuchi, T., Kawaguchi, H., Sekiguchi, F. and Sunano, S. (2003). Effects of L-arginine on spontaneous contraction of the rat portal vein. Pflügers Arch. 446: 30-35. 
Shoji, T., Tsuru, H. and Shigei, T. (1983). A regional differences in the distribution of post synaptic alpha adrenoceptor subtypes in canine veins. Naunyn-Schmiedeberg's Arch. Pharmacol. 324: 246-255.

Szatmari, V., van den Ingh, T.S., Fenyves, B., Sotonyi, P., Kotai, I., Petrasi, Z. and Voros, K. (2002). Portal hypertension in a dog due to circumscribed fibrosis of the wall of the extrahepatic portal vein. Vet. Rec. 150: 602-605.

Thorin, E., Huang, P.L., Fishman, M.C. and Bevan, J.A. (1998). Nitric oxide inhibits $\alpha_{2}$-adrenoceptormediated endothelium-dependent vasodilation. Circ. Res. 82: 1323-1329.

Vedernikov, Y.P., Vihert, A.M. and Leisner, H. (1987). Arterial endothelium-derived relaxing factor (AEDRF) does not suppress papillary muscle or portal vein contractions. Eur. J. Pharmacol. 142: 471-474.

Willett, I.R., Esler, M., Jennings, G. and Dudley, F.J. (1986). Sympathetic tone modulates portal venous pressure in alcoholic cirrhosis. Lancet 2: 939-942.

Wing, L.M., Reid, J.L., Davies, D.S., Neill, F.A., Tippett, P. and Dollery, C.T. (1977). Pharmacokinetic and concentration-effect relationship of clonidine in essential hypertension. Eur. J. Clin. Pharmacol. 12: 463-469.

Yang, D., Feletou, M., Boulanger, C.M., Wu, H.F., Levens, N., Zhang, J.N. and Vanhoutte, P.M. (2002). Oxygen-derived free radicals mediate endothelium-dependent contraction to acetylcholine in aortas from spontaneously hypertensive rats. Br. J. Pharmacol. 136: 104-110.

Yang, D., Feletou, M., Levens, N., Zhang, J.N. and Vanhoutte, P.M. (2003). A diffusible substance(s) mediates endothelium-dependent contractions in the aorta of SHR. Hypertens. 41: 143-148.

Yomaida, I., Murao, M., Togashi, H., Shimamura, K., Koike, Y. and Saito, H. (1979). Effects of long-term administration and withdrawal of clonidine on activity of sympathetic efferent nerve unit in spontaneously hypertensive rats. Neurosci. Lett. 15: 249-251. 